\title{
Erratum to: Cerebrospinal fluid HIV viral load in different phases of HIV-associated brain disease
}

Hans-Jürgen von Giesen • Ortwin Adams •
Hubertus Köller • Gabriele Arendt

Published online: 21 July 2010

(C) Springer-Verlag 2010

Erratum to: J Neurol (2005) 252:801-807

DOI 10.1007/s00415-005-0749-4

Acknowledgment: The authors thank Mrs. Heike Ebel for her part in data acquisition as part of her doctoral thesis.

The online version of the original article can be found under doi:10.1007/s00415-005-0749-4.

H.-J. von Giesen ( $₫)$

Dept. of Neurology, Heinrich-Heine-Universität, Düsseldorf, Postfach 1010 07, 40001 Düsseldorf, Germany

e-mail: h-j.vgiesen@maria-hilf.de

O. Adams

Dept. of Diagnostic Virology, Heinrich Heine University,

Düsseldorf, Germany

H. Köller · G. Arendt

Dept. of Neurology, Heinrich Heine University, Düsseldorf,

Germany 